\title{
Rancang Bangun Aplikasi Manpower Request Bagian Recruitment pada PT Dynapack Asia
}

\author{
Listiani $^{1}$, Friska Natalia ${ }^{2}$ \\ Program Studi Sistem Informasi, Universitas Multimedia Nusantara, Tangerang Selatan, Indonesia \\ listiani@student.umn.ac.id \\ friska.natalia@umn.ac.id
}

Diterima 24 Januari 2019

Disetujui 24 Juni 2019

\begin{abstract}
PT Dynapack Indonesia consists of several divisions, one of them is IT division which has Application Development sub division that is in charge of designing and developing application which is needed for the company. PT Dynapack Indonesia is a multinational company, that it is necessary to maintain the quality of Human Resources, considering the Human Resources (HR) division is a strategic factor for both profit organizations and non-profit organizations [1] . Therefore, the IT division of PT Dynapack Indonesia developed a web-based Manpower Request application system with the purpose of assisting HR division in recruiting process to data archiving. Development of Manpower Request application system uses CodeIgniter framework, jQuery, Metronic, Bootstrap, SAP and MySQL database. Testing, fixing bugs, and updates has been done while the application was being developed. Manpower Request application is ready to use and has been made in accordance with requirements.

Keywords - CodeIgniter, Human Resources, Recruitment, website
\end{abstract}

\section{Pendahuluan}

Seiring berkembangnya teknologi, pencarian terhadap sesuatu sangat bergantung pada teknologi dan berdasarkan riset sebelumnya ada aplikasi yang digunakan untuk menemukan alergi dalam bentuk website [2] dan untuk menemukan rute terpendek yang dibuat berbasis android [3]. Pada penelitian ini akan dibuat suatu aplikasi berbasis website untuk meningkatkan efisiensi dalam rekrutmen dan pencatatan kebutuhan tenaga kerja.

PT Dynapack Asia merupakan perusahaan rigid packaging yang memiliki 10 perusahaan serta 20 pabrik manufaktur di 5 negara (Indonesia, Thailand, Vietnam, Malaysia, dan China). PT Dynapack Indonesia merupakan salah satu bagian dari Dynapack Asia yang bertempat di Indonesia. Perusahaan ini menggunakan SAP untuk melakukan integrasi antar perusahaan dalam Dynapack Asia.
PT Dynapack Indonesia telah menggunakan teknologi informasi untuk membantu proses bisnis yang berjalan, namun masih ada beberapa hal yang berjalan secara manual, seperti: proses rekrutmen calon pekerja dan proses permintaan tambahan pekerja. Pada perusahaan multinasional seperti Dynapack, diperlukan efisiensi kinerja dalam setiap proses bisnis. Agar dapat meningkatkan efisiensi dalam rekrutmen dan pencatatan kebutuhan tenaga kerja, divisi Human Resources pada PT Dynapack Indonesia memutuskan untuk melakukan automasi proses rekrutmen dengan membuat sistem aplikasi rekrutmen berbasis web.

\section{LANDASAN TEORI}

\section{A. Pemrograman Berorientasi Objek}

Pemrograman berorientasi objek merupakan praktik menciptakan arsitektur perangkat lunak yang memungkinkan fleksibilitas melalui desain yang bersifat modular.

Pemrograman berorientasi objek bukan merupakan bahasa, melainkan merupakan konsep berpikir dibalik pengembangannya [2].

\section{B. $P H P$}

PHP merupakan bahasa server-side yang didesain untuk membangun aplikasi berbasis website. PHP telah digunakan oleh beberapa aplikasi manajemen konten bisnis online, selain itu juga merupakan alat pengembangan situs web dinamis. Kode PHP dapat disisipkan dengan mudah di dalam bahasa HTML. PHP mendukung banyak basis data, seperti: MySQL, Generic ODBC, Solid, dan Oracle [4].

\section{Metode Penelitian}

\section{A. Metode Pengumpulan Data}

Data yang dibutuhkan serta alur sistem didapatkan melalui observasi serta wawancara di Dynapack Asia pada tanggal 3 Juli 2017 hingga 5 Juli 2017.

\section{B. Metode Pengembangan Sistem}

Implementasi model akan dibangun dengan menggunakan metode Rapid Application 
Development. Berikut ini merupakan tahapan pengembangan sistem yang digunakan:

1. Analisa dan Perancangan Sistem

Pada tahap ini, dilakukan wawancara dengan divisi Human Resource serta observasi langsung untuk mengetahui masalah dan proses bisnis yang terjadi pada proses rekrutmen dan proses permintaan karyawan baru.

Setelah mengetahui proses bisnis yang berjalan serta masalah yang perlu diselesaikan, dilakukan analisa dan perancangan sistem yang dapat menyelesaikan masalah yang ada.

\section{Pengembangan Antar Muka}

Antar muka aplikasi dikembangkan berdasarkan analisa sistem yang telah dilakukan pada tahap sebelumnya. Antar muka dikembangkan dengan menggunakan Axure RP 7.

3. Implementasi

Basis data serta sistem fungsional dibangun di tahap ini. Sistem fungsional serta basis data diimplementasikan terhadap antar muka yang telah dikembangkan pada tahap sebelumnya. Implementasi sistem fungsional dilakukan menggunakan bahasa pemrograman PHP dan kerangka kerja CodeIgniter

4. Pengujian dan Pemeliharaan

Pengujian dilakukan untuk memastikan bahwa program berjalan sesuai yang diharapkan. Setelah lolos tahap pengujian, sistem aplikasi Manpower Request dapat digunakan oleh seluruh karyawan Dynapack Asia.

Pemeliharaan aplikasi dilakukan agar aplikasi Manpower Request tetap relevan mengikuti perkembangan teknologi dan proses bisnis.

5. Dokumentasi

Dokumentasi merupakan bagian yang penting dalam proses pengembangan sistem aplikasi. Dan yang paling penting, menghilangkan mendokumentasikan proses pengembangan dapat menyebabkan hilangnya data perusahaan [5].

\section{HASIL DAN PEMBAHASAN}

\section{A. Analisa dan Perancangan Sistem}

Hasil analisa didapatkans setelah wawancara dengan divisi Human Resource serta observasi langsung untuk mengetahui masalah dan proses bisnis yang terjadi pada proses rekrutmen dan proses permintaan karyawan baru. Oleh karena itu, sebelum masuk ke dalam pengembangan sistem, diperlukan alur sistem yang jelas agar pengembangan sistem tidak terhambat. Sistem aplikasi rekrutmen berbasis web yang selanjutnya akan disebut Manpower Request bagian rekrutmen memiliki beberapa fitur yaitu:

- Fitur Create Request

- $\quad$ Fitur Update Request

- Fitur History Request

- $\quad$ Fitur Request Next List

- Fitur Pretest

○ Fitur HR Interview
- Fitur Psychological Test

- Fitur User Interview

- Fitur Offering

- Fitur Medical Checkup

- Fitur Finalize

\section{A.1. Fitur Create Request}

Pengguna dapat membuat permintaan untuk tenaga kerja baru. Setelah divisi Human Resources menerima permintaan, divisi Human Resources akan memutuskan apakah permintaan ini layak untuk diterima.

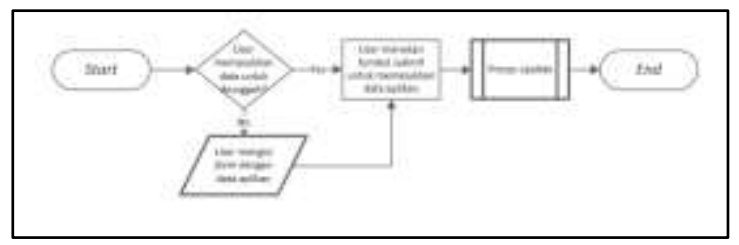

Gambar 1. Flowchart Fitur Create Request

\section{A.2. Fitur Update}

Pengguna yang telah membuat permintaan dapat mengubah dokumen permintaan yang sudah diajukan selama divisi Human Resources belum melakukan proses update.

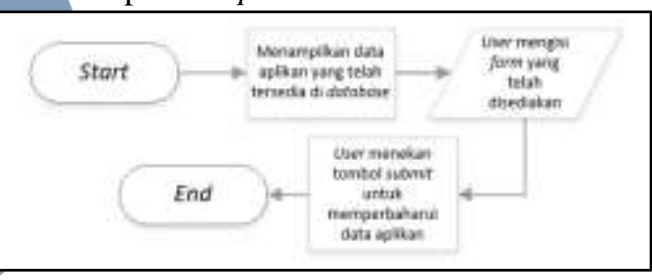

Gambar 2. Flowchart Fitur Create Request

\section{A.3. Fitur History Request}

Pengguna yang telah membuat permintaan dapat memantau status permintaan yang telah diajukan.

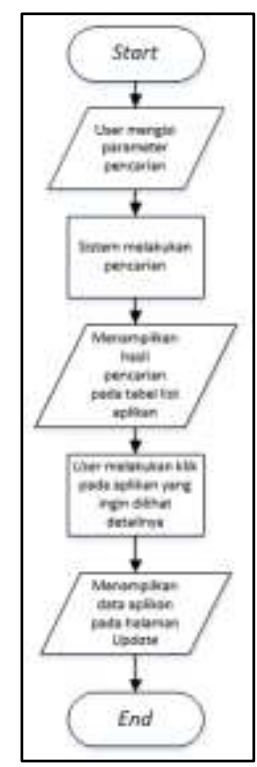

Gambar 3. Flowchart Fitur History Request 


\section{A.4. Fitur Request Next List}

Apabila permintaan disetujui oleh divisi Human Resources(HR), kini permintaan akan muncul di halaman Next List sehingga HR dapat memulai proses rekrutmen.

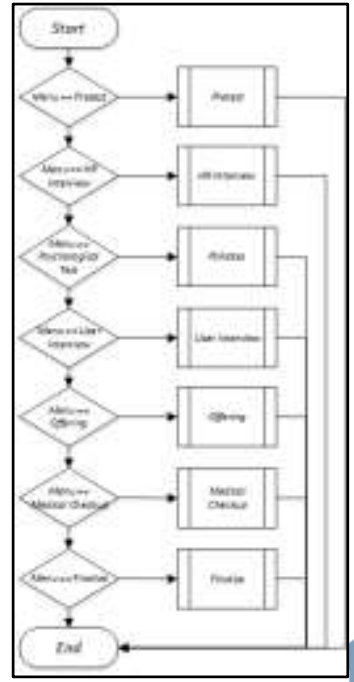

Gambar 4. Flowchart Fitur Request Next List

1. Fitur Pretest

Pada fitur ini, pengguna dapat memasukkan hasil Pretest aplikan. Sistem akan memeriksa apakah ada status gagal disalah satu proses HR Interview, Psikotest, User Interview, Offering, Finalize. Jika ditemukan kegagalan disalah satu proses, pengguna tidak dapat menambahkan data Pretest. Setelah pengguna menambahkan data Pretest, pengguna memutuskan apakah data yang dimasukkan sudah bersifat final. Jika dianggap sudah final, maka pengguna dapat memberikan tanda check pada kotak check yang tersedia. Kemudian, pengguna menekan tombol Submit untuk melakukan validasi data kemudian memasukkan data ke dalam database.

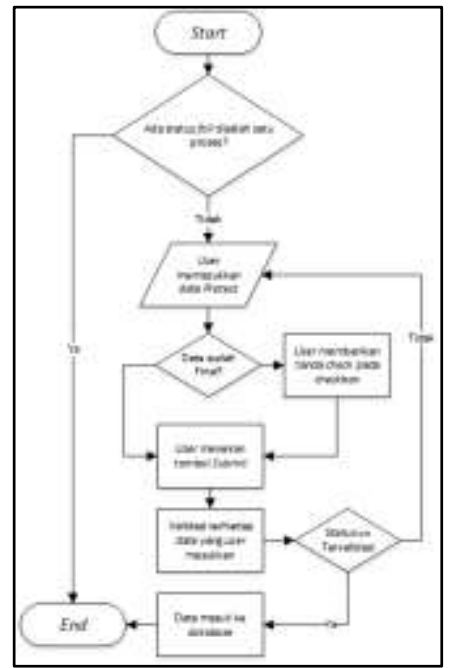

Gambar 5. Flowchart Fitur Pretest
2. Fitur HR Interview

Pada fitur ini, pengguna dapat memasukkan hasil HR Interview aplikan. Sistem akan memeriksa apabila ada status gagal di salah satu proses. Jika tidak ada, pengguna dapat memasukkan tanggal Interview oleh HR. Setelah HR melakukan interview dengan aplikan, pengguna akan memasukkan data hasil interview HR. Apabila data yang dimasukkan sudah final, pengguna memberikan tanda check pada checkbox yang tersedia. Setelah mengisi data, pengguna menekan tombol Submit dan sistem akan melakukan validasi terhadap data yang dimasukkan oleh pengguna. Apabila data lolos proses validasi, data akan masuk ke database.

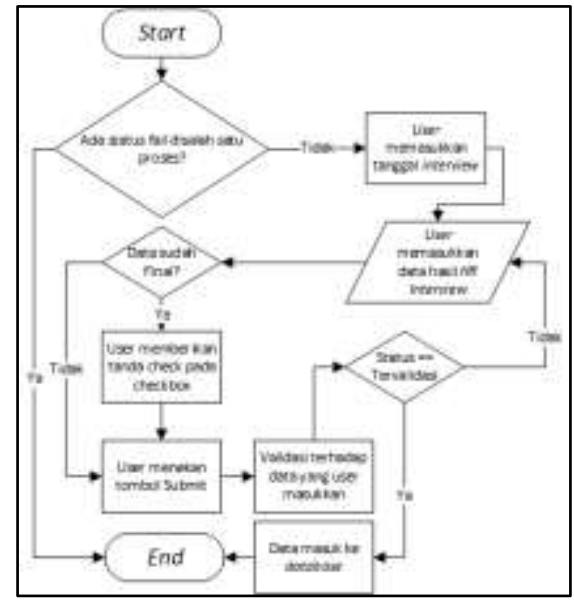

Gambar 6. Flowchart Fitur HR Interview

3. Fitur Psychological Test

Pada fitur ini, pengguna dapat memasukkan hasil Psikotes aplikan. Pada bagian Psikotes, sistem akan memeriksa apabila ada status gagal di salah satu proses. Jika tidak ada, pengguna dapat memasukkan tanggal Psikotes. Setelah aplikan melakukan psikotes, data hasil tes perlu dilampirkan ke sistem. Apabila data yang dimasukkan sudah final, pengguna memberikan tanda check pada checkbox yang tersedia. Tanda checkbox berarti data sudah tidak dapat diubah lagi. Setelah mengisi data, pengguna menekan tombol Submit dan sistem akan melakukan validasi terhadap data yang dimasukkan oleh pengguna. Apabila data lolos proses validasi, data akan masuk ke database. 


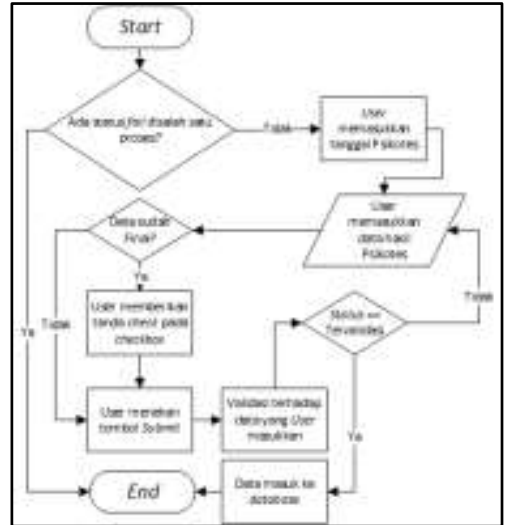

Gambar 7. Flowchart Pretest

4. Fitur User Interview

Pada fitur ini, pengguna dapat memasukkan hasil User Interview aplikan. Pada bagian User Interview, sistem akan memeriksa apabila ada status gagal di salah satu proses. Jika tidak ada, pengguna dapat menjadwalkan tanggal untuk melakukan User Interview. Sistem akan mengirimkan e-mail ke user yang akan melakukan interview tiga hari dan satu hari sebelum tanggal interview yang dijadwalkan. User merupakan calon atasan dari aplikan tersebut saat ia bekerja. Setelah User melakukan interview dengan aplikan, seluruh data hasil interview perlu dilampirkan dalam sistem. Apabila data yang dimasukkan sudah final, pengguna memberikan tanda check pada checkbox yang tersedia. Setelah mengisi data, pengguna menekan tombol Submit dan sistem akan melakukan validasi terhadap data yang dimasukkan oleh pengguna. Apabila data lolos proses validasi, data akan masuk ke database.

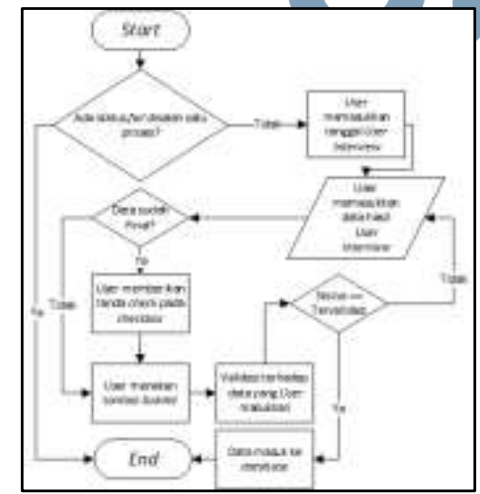

Gambar 8. Flowchart User Interview

\section{Fitur Offering}

Pada fitur ini, pengguna dapat memasukkan hasil Offering aplikan. Sistem akan memeriksa apabila ada status gagal di salah satu proses. Jika tidak ada, pengguna dapat memasukkan tanggal Interview oleh HR. Setelah HR melakukan interview dengan aplikan, pengguna akan memasukkan data hasil interview HR. Apabila data yang dimasukkan sudah final, pengguna memberikan tanda check pada checkbox yang tersedia. Setelah mengisi data, pengguna menekan tombol Submit dan sistem akan melakukan validasi terhadap data yang dimasukkan oleh pengguna. Apabila data lolos proses validasi, data akan masuk ke database.

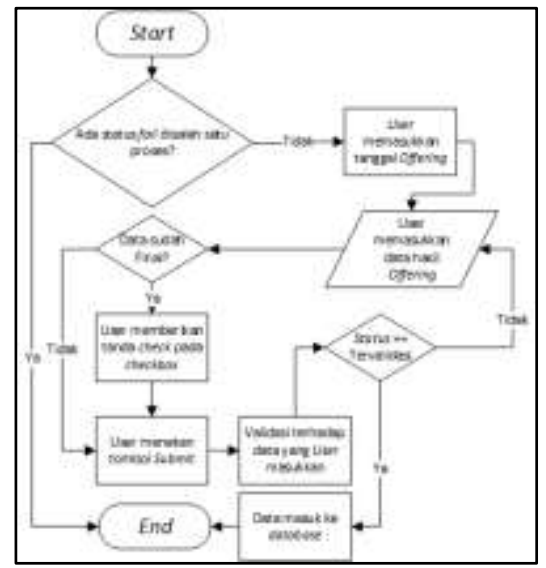

Gambar 9. Flowchart Offering

6. Fitur Medical Checkup

Pada fitur ini, pengguna dapat memasukkan hasil Medical Checkup aplikan. Sistem memeriksa apabila ada status gagal di salah satu proses. Selain itu, sistem juga memeriksa apakah aplikan sudah lolos tahap offering. Jika sudah lolos tahap offering dan belum ada status gagal pada seluruh proses, pengguna dapat memasukkan tanggal Medical Checkup. Setelah aplikan menyelesaikan medical checkup, pengguna melampirkan dokumen medical checkup sebelum menetapkan status tes aplikan. Apabila data yang dimasukkan sudah final, pengguna memberikan tanda check pada checkbox yang tersedia. Setelah mengisi data, pengguna menekan tombol Submit dan sistem akan melakukan validasi terhadap data yang dimasukkan oleh pengguna. Apabila data lolos proses validasi, data akan masuk ke database.

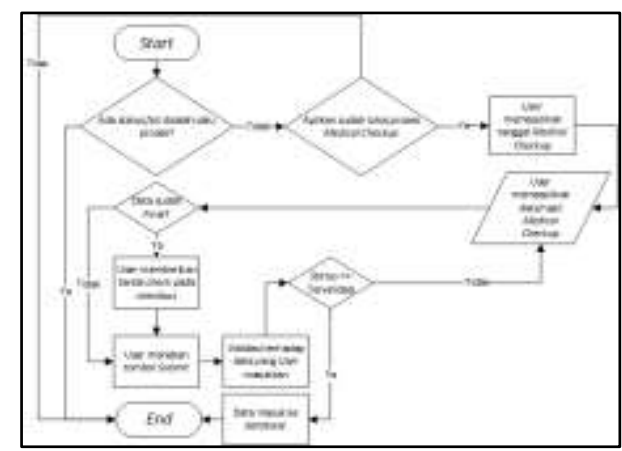

Gambar 10. Flowchart Medical Check-up

7. Fitur Finalize

Pada fitur ini, pengguna dapat memasukkan hasil Finalize aplikan. Sistem akan 
melakukan pemeriksaan, apakah aplikan yang bersangkutan telah memenuhi ketentuan yang dibutuhkan. Agar seorang aplikan dapat dihire, aplikan perlu memenuhi syarat berikut ini:

- Tidak ada status gagal di salah satu proses

- Aplikan sudah lolos Medical Checkup

- Aplikan belum dipekerjakan di nomor request manapun

- Jumlah karyawan yang dibutuhkan belum mencukupi

Kemudian, divisi Human Resources (HR) akan menganalisa dan membuat pilihan untuk menolak aplikan atau menerima aplikan. Apabila HR memutuskan untuk menerima aplikan, pengguna akan mengisi beberapa data kemudian menekan tombol Hire, setelah data tervalidasi, data akan masuk ke dalam database.

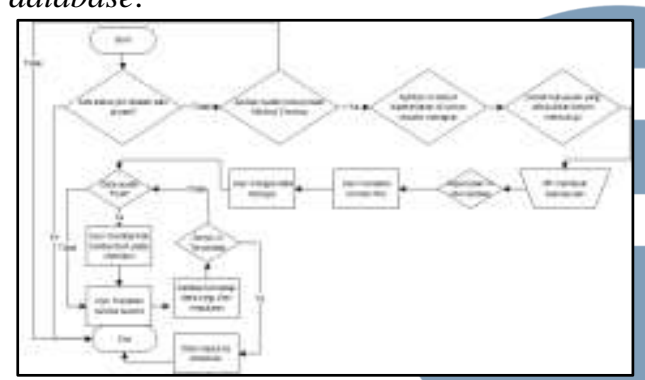

Gambar 11. Flowchart Finalize

\section{B. Pengembangan Antar Muka}

Setelah mengetahui secara jelas alur sistem, dilakukan pengembangan antar muka untuk setiap proses.

Gambar 12 menunjukkan antar muka halaman untuk membuat permintaan tenaga kerja baru.

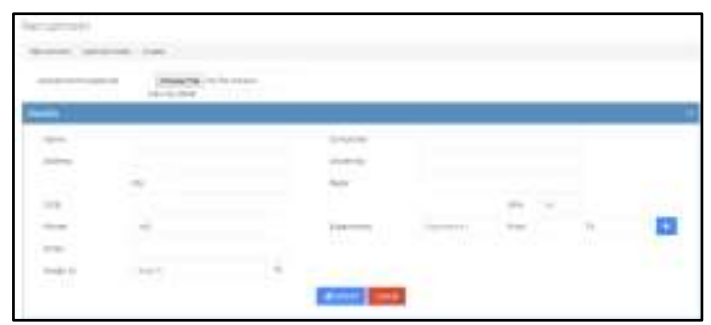

Gambar 12. Antar Muka Halaman Create Request

Gambar 13 menunjukkan antar muka halaman untuk menampilkan history permintaan tenaga kerja yang telah dibuat.

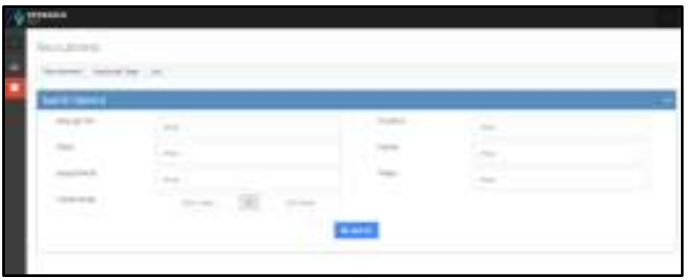

Gambar 13. Antar Muka Halaman History Request
Gambar 14 menunjukkan antar muka halaman Recruitment - Next List yang digunakan untuk melihat Request yang telah mendapatkan persetujuan dari pihak yang bersangkutan dan tersedia untuk melakukan proses hiring.

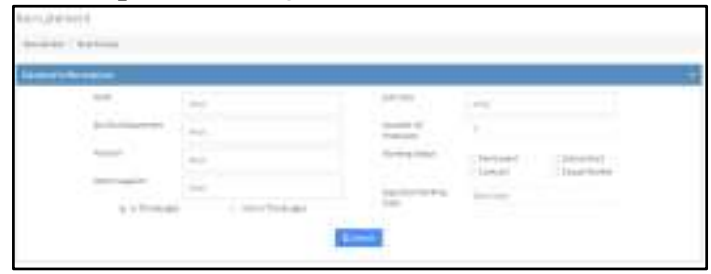

Gambar 14. Antar Muka Halaman Next List

Gambar 15 merupakan antarmuka halaman Pretest, HR Interview, Psychological Test, User Interview, Offering, serta Medical Checkup. Keenam bagian tersebut akan memiliki antarmuka yang sama. Pengguna dapat menjadwalkan serta menyimpan data hasil proses yang bersangkutan.

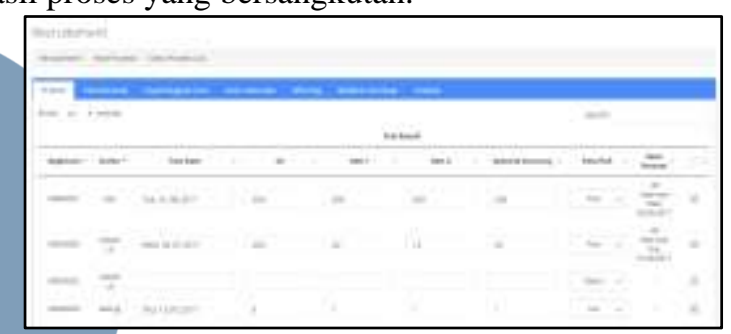

Gambar 15. Antar Muka Halaman Pretest

Gambar 16 merupakan antarmuka halaman Finalize yang digunakan untuk menentukan apabila kandidat tersebut lolos dan berhak menjadi karyawan Dynapack Asia.

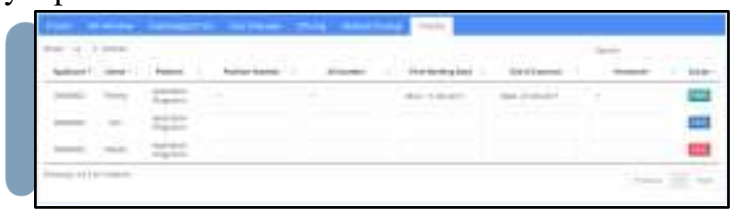

Gambar 16. Antar Muka Halaman Finalize

\section{Implementasi}

Implementasi dilakukan dengan menggunakan bahasa pemrograman PHP dengan framework CodeIgniter, serta menggunakan MySQL sebagai database.

\section{Testing dan Maintenance}

Testing dilakukan untuk memastikan bahwa sistem yang dibangun telah bebas dari kesalahan dan sesuai dengan permintaan client. Dalam kasus ini, divisi Human Resources adalah sebagai user dari testingnya. Proses maintenance juga masih berlangsung hingga sekarang. Tahap terakhir adalah melakukan perpindahan dari sistem yang lama ke sistem yang baru. Sebelum adanya Manpower Request, seluruh proses bersifat manual atau hanya dilakukan pertukaran dokumen secara fisik. Proses elektronik hanya terjadi pada saat proses hiring. Divisi Human Resources akan memasukkan data tenaga kerja baru ke dalam sistem SAP. 
Dengan adanya Manpower Request pertukaran dokumen secara fisik dapat diganti menjadi pertukaran informasi secara elektronik dan lebih mudah dalam melakukan proses integrasi antar perusahaan manufaktur serta menghindari redudansi data. Redudansi data yang dimaksud adalah jika calon tenaga kerja A pernah melamar di salah satu perusahaan Dynapack, kemudian ditolak, namun suatu saat ketika ia melamar ulang, bagian Human Resources tidak perlu memasukkan datanya lagi. Sistem akan mendeteksi serta memberikan notifikasi bahwa orang tersebut sudah ada di dalam database.

Konversi sistem terdiri dari empat pendekatan, yaitu: pendekatan langsung, paralel, phase-in, serta pilot [5]. Pendekatan yang digunakan pada studi kali ini merupakan pendekatan paralel, yaitu sistem lama tetap digunakan sambil menggunakan sistem baru.

\section{E. Dokumentasi}

Pada tahap ini dilakukan penulisan dokumentasi mengenai fungsi, alur proses, serta user guide yang digunakan pada saat dilakukan sosialisasi mengenai sistem aplikasi Manpower Request.

\section{A. Kesimpulan}

\section{SIMPULAN}

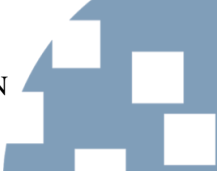

Aplikasi Manpower Request berbasis web bagian Recruitment telah berhasil dirancang dan dibangun pada PT Dynapack Indonesia. Aplikasi ini dibangun dengan framework CodeIgniter dan memiliki beberapa fitur, yaitu fitur penambahan data aplikan menggunakan form excel, fitur reporting, fitur Next Process untuk mengakomodir proses tes yang akan dilalui aplikan hingga akhirnya divisi Human Resources dapat melakukan proses hiring pada aplikan tersebut. Aplikasi ini dapat diakses lewat sistem intranet perusahaan, sehingga dapat diakses dengan mudah oleh karyawan Dynapack Asia.

\section{B. Saran}

Adapun beberapa saran untuk penelitian selanjutnya:

1. Penambahan grafik interaktif pada bagian reporting agar pengguna lebih mudah untuk menangkap maksud dari laporan tersebut.

2. Migrasi dari dokumen lampiran hasil tes/interview menjadi form di website yang dapat diakses kapanpun, agar analisa data lebih mudah dilakukan

\section{DAFTAR PUSTAKA}

[1] T. Yuniarsih and M. D. Sugiharto, "Human Resource Management Model to Create Superior Performance," International Journal of Education, pp. 74-81, 2016.

[2] A. Halim, F.N. Ferdinand, C. S. Ko (2018), Ontology-Based Decision Support System for Hypersensitivity Disorder Allergy, ICIC Express Letters, vol.12, no.8, pp.847-854

[3] DJIKSTRA Algorithm Based Approach to Shortest Path Model in Public Bus Transportation, International Journal of Computer Science and Engineering (IJCSE), Vol 7 No.6., pp $1-8$

[4] B. Smith, Advanced ActionScript 3, New York: Springer, 2015.

[5] Bello and R. Oluwaseun, "A University Examination Web Application Based on Linear-Sequential Life Cycle Model," DIU Journal of Science and Technology, vol. 12, no. 1, 2017.

[6] M. F. F. A. Nasution and H. R. Weistroffer, "Documentation in Systems Development: A Significant Criterion for Project Success," Hawaii International Conference on System Sciences, 2009.

[7] M. B. Romney and P. J. Steinbart, Accounting Information Systems, Global Edition, Harlow: Pearson Education Limited, 2014. 